\title{
Ge匇?отато
}

\section{Geo data for late blight control in potato Results of retailer survey in Rangpur, Bangladesh 2018-2019}

K.J. Hossain, S.M.M

Rahman, H. Hengsdijk

\section{GEOPOTATO}

External Report 7
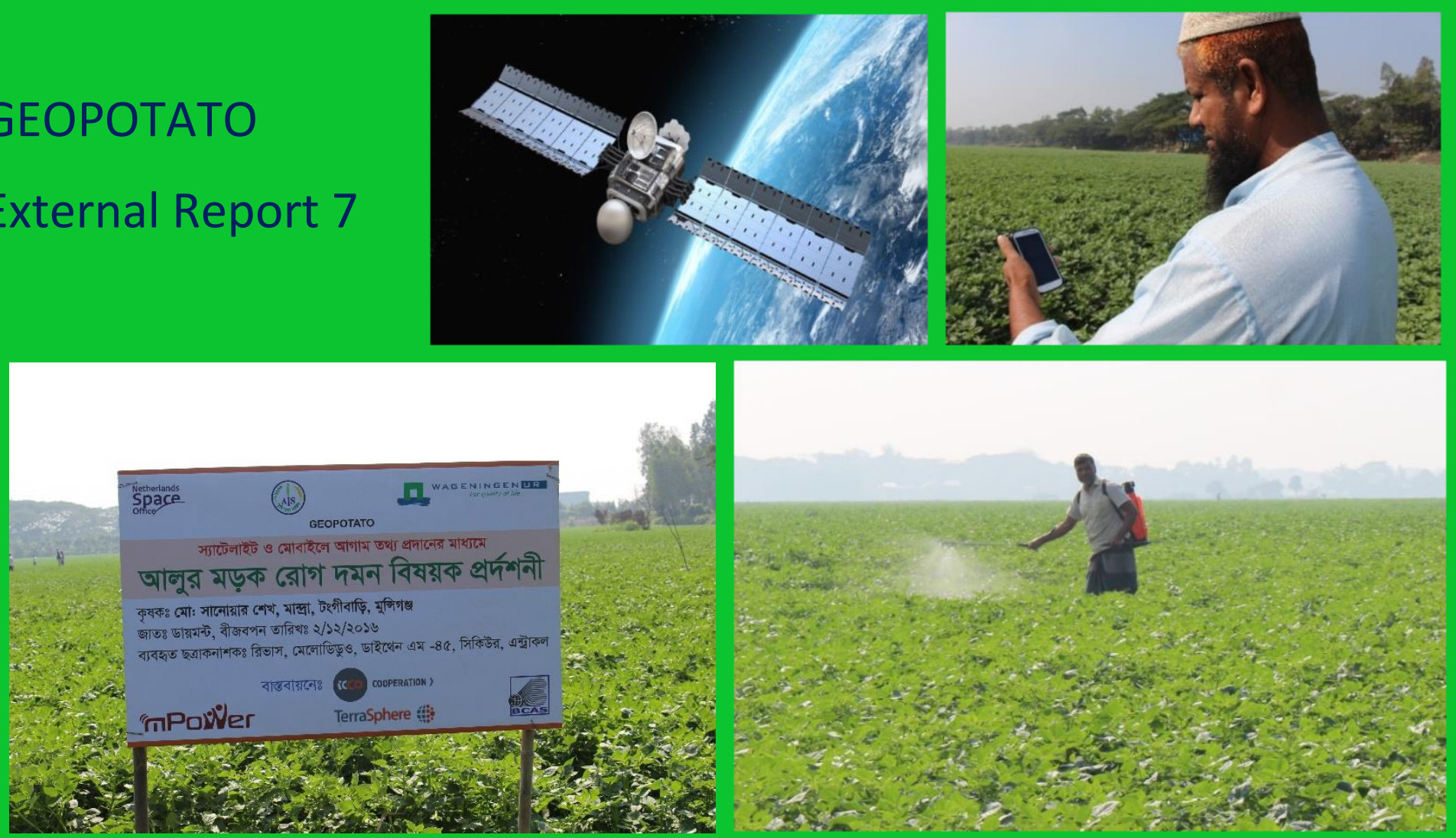


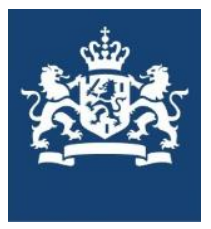

The GEOPOTATO project develops and implements a decision support service (DSS) in Bangladesh to control the late blight disease in potato. Satellite data and various models are important aspects of the DSS. GEOPOTATO aims at becoming the preferred agricultural advice service for potato farmers in Bangladesh. GEOPOTATO is financed by the G4AW program of the Dutch Ministry of Foreign Affairs, which is executed by the Netherlands Space Office (NSO).

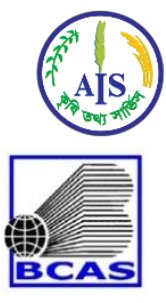

isco

\section{"TPaiver}

Agricultural Information Services, Ministry of Agriculture, Bangladesh

Bangladesh Centre for Advanced Studies, Bangladesh

ICCO Cooperation, Bangladesh

mPower Social Enterprise Ltd., Bangladesh

TerraSphere 帒: $\quad$ TerraSphere, The Netherlands

WAGENINGEN

Wageningen University \& Research, The Netherlands

Suggested citation for this report:

Hossain, K.J., Rahman, S.M.M., Hengsdijk, H., 2019. Geo data for late blight control in potato. Results of retailer survey in Rangpur, Bangladesh 2018-2019. GEOPOATO Report 7. Dhaka / Wageningen

DOI: https://doi.org/10.18174/517166

\section{(c) $(1)(2)(2)$}

GEOPOTATO uses a Creative Commons Attribution-Non-Commercial-Share Alike 4.0 International License for its reports

The user may copy, distribute and transmit the work and create derivative works. Third-party material that has been used in the work and to which intellectual property rights apply may not be used without prior permission of the third party concerned. The user must specify the name as stated by the author or licence holder of the work, but not in such a way as to give the impression that the work of the user or the way in which the work has been used are being endorsed. The user may not use this work for commercial purposes. 
GE冈

\section{Geo data for late blight control in potato}

Results of retailer survey in Rangpur, Bangladesh 2018-2019

K.J. Hossain, S.M.M Rahman, H. Hengsdijk

GEOPOTATO External Report 7 


\section{Table of Contents}

Executive summary ......................................................................................

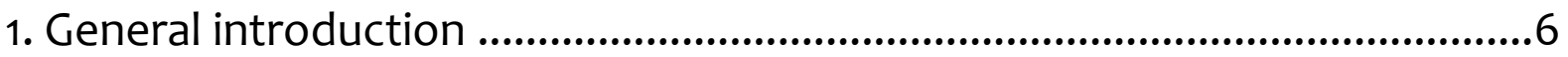

2. GEOPOTATO service.....................................................................................

2.1 Why branded alerts? ........................................................................................

2.2 The role of agro-retailers ................................................................................

2.3 Collaboration with Bayer Crop Science ...................................................8

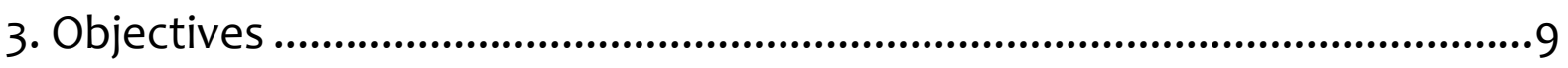

4. Methodology ........................................................................................................ 10

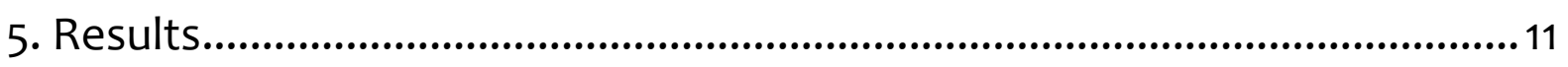

5.1 Agro-input retailers' knowledge of fungicide company names ...............11

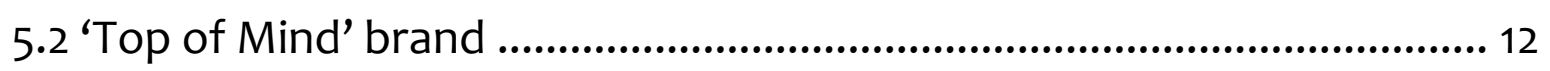

5.3. Change in Bayer fungicide product sales ................................................ 13

5.4 Impact of GEOPOTATO branded message on sales of Bayer products 14

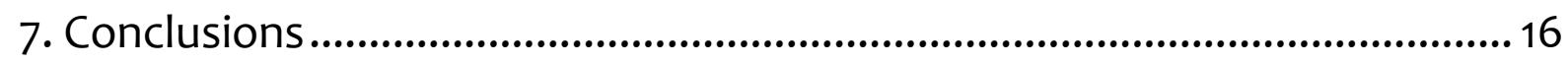

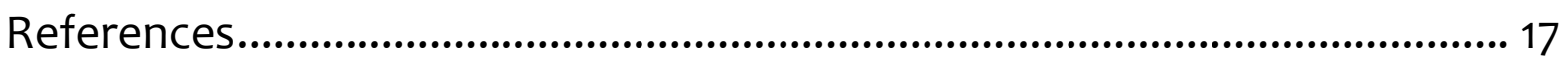

Annex 1: Baseline Questionnaire .................................................................. 18

Annex 2: Endline Questionnaire ................................................................ 19 


\section{Executive summary}

GEOPOTATO is a decision support service (DSS) that combines satellite image processing data of crop biomass growth and real-time weather data from ground weather stations to identify conducive conditions for the fungal disease late blight. When such conditions are forecasted, potato farmers receive an early warning via SMS and Voice Message to take proper control measures by timely applying fungicides.

To strengthen the business proposition of the DSS, the GEOPOTATO consortium has collaborated for two years with Bayer Crop Science in Bangladesh. In the Rabi season of 2018-19 5,564 registered GEOPOTATO farmers in the upazillas Badarganj and Pirganj of Rangpur district received so-called 'branded' SMS / Voice Messages that had recommendations to use specific Bayer products.

Traditionally, local agro-retail shops are important sources of information and knowledge related to the control of late blight for farmers in Bangladesh. Because of the key role of agro-retail shops in the information and knowledge chain, better understanding is needed on how a new information service like GEOPOTATO influences agro-retail shops, i.e. fungicide brand recognition and fungicide sales. Therefore, we carried out a study in the 2018-2019 season under agro-retail shops in Badarganj and Pirganj. In total 124 shop owners were interviewed at the start of the season and again at the end of the season to understand the effect of the GEOPOTATO service on fungicide sales and brand recognition.

The main results include:

- Knowledge of Bayer among local retailers has increased after one season with GEOPOTATO branded SMS / Voice mail alerts.

- Branded GEOPOTATO recommendations have placed Bayer products at the 'Top of Mind' brand among retailers.

- More local retailers sold Bayer products in the 2018-2019 season. Especially more retailers sold Melody Duo than in earlier seasons.

- More than $70 \%$ of the retailers have seen the GEOPOTATO SMS messages shown by farmers and more than $80 \%$ of these retailers sold sometimes or always Bayer products.

Awareness on the potentials of using the GEOPOTATO service as an integrated advisory and marketing tool is of interest to support the service and eventually scale out the service to other areas of Bangladesh together with partners in the agro-input sector. 


\section{General introduction}

GEOPOTATO is a geodata-driven decision support service (DSS) that uses satellite imagery and weather data to predict outbreaks of late blight in potato crops. Late blight (Phytophthora infestans) is the most common and destructive fungal disease in potatoes. Annual yield losses in Bangladesh due to late blight have been estimated at $25-57 \%$ (Rahman et al., 2008). Late blight can be controlled by the application of fungicides, but the degree of control depends on the timing of the fungicide application in relation with crop development, disease intensity and weather conditions. The efficiency of late blight control can be improved by the timely application of fungicides. Through an SMS platform, GEOPOTATO warns farmers for potential late blight outbreaks which allows farmers to take prompt control measures. Hence, the service potentially increases the efficiency of late blight control, thus reducing environmental and financial costs and increases crop yields and profits of farmers. The GEOPOTATO project is funded by the Netherlands Space Office and is implemented by a Dutch-Bangla consortium comprising mPower Social Enterprises Ltd., Wageningen University \& Research, Agriculture Information Service, ICCO Cooperation, TerraSphere and Bangladesh Center for Advanced Studies.

In the potato growing season of 2016-17, the GEOPOTATO service was piloted among 120 farmers in the Munshiganj district of Bangladesh. In the 2017-18 season 6,453 farmers from eight sub-districts (upazillas) of Rangpur and six upazillas of Munshiganj were registered service users. In the first two seasons the advice did not consider differences in crop development among farmer fields. In the 2018-19 season, information on the time of planting of registered users was available which allowed to target the advice better to the crop development. In addition, the GEOPOTATO service area was expanded to six upazillas in the Dinajpur district. In total 41,812 potato farmers in three districts were registered in the 2018-2019 season and they received SMS / Voice message alerts from October 2018 to March 2019.

This study reports on a pilot in two upazillas (Badarganj and Pirganj) of Rangpur where 5,564 subscribed farmers received SMS / Voice messages in the 2018-2019 season with explicit advice to use specific fungicide types of the Bayer brand. The hypothesis is that these so-called 'branded alerts' likely result in farmers purchasing and using premium fungicides for late blight control. This gives a potential win-win situation for both farmers and fungicide producers: Farmers are supported to take well-informed decisions concerning late blight control, which contributes to sustainable farming practices. At the same time a fungicide producer can promote a specific fungicide brand resulting in increased sales.

The acceptance of the GEOPOTATO service by local agro retailers is important as they currently fulfill an important advisory role for farmers. Hence, understanding the effect of GEOPOTATO's branded alerts on brand recognition and sales is necessary to use this service more effectively and harness its potential. This report describes the results of an exploratory study carried out under local agro-retailers in Badarganj and Pirganj. Over 100 agro-retailers were interviewed at the start of the potato growing season and after the growing season. 


\section{GEจำคTato}

\section{GEOPOTATO service}

\subsection{Why branded alerts?}

The objective for using brand names of fungicides in the alert messages is twofold: First, it improves the GEOPOTATO service as it allows to provide advice on using fungicides with specific modes of actions, i.e. fungicides with preventive properties to minimize crop infection in the beginning of the growing season and fungicides with more curative properties that are more effective under high infection pressure later in the growing season. Many farmers in Bangladesh are not aware of the differences in the mode of action of fungicides. Mentioning the fungicide brand name in the alert message will help farmers to buy and apply fungicides with the proper mode of action. Second, provision of a brand name in the alert message is of potential interest for fungicide producers and suppliers as the GEOPOTATO service can be used as a marketing tool. Farmers are supported to take well-informed decisions concerning late blight control, which contributes to sustainable farming practices, while at the same time a fungicide type of a specific brand can be promoted. Awareness on the potentials of using the GEOPOTATO service as an integrated advisory and marketing tool is of interest to support the service and eventually scale out the service to other areas of Bangladesh together with partners in the agro-input sector.

\subsection{The role of agro-retailers}

Currently, farmer's decision to apply a specific fungicide type and brand depends on many factors, such as the costs of the fungicide product, farmer' knowledge on the mode of action of fungicides, trust in the product, and the advice of family/friends, extension and agro-input dealers. In Bangladesh and in many other less-developed countries, local agroretail shops play an important advisory role. Agro-retail shops have the overview of the available products and a better understanding than most farmers on the mode of action of the various fungicides. A study from 2011 showed that the private sector is the principal source of pesticide use information for $65 \%$ of the farmers in Bangladesh (Katalyst, 2012).

Although local agro-input retailers currently fulfil an important advisory role for farmers in the choice for a fungicide, they may have different and potentially conflicting aims than farmers. For example, agro-input retailers may be enticed to advice those fungicides that are available in-stock or that have the largest financial margin. A related issue is that there are many generic fungicides, i.e. implying that the active ingredient of these fungicides is the same. Because the patent on the active ingredient is expired, generic fungicides are manufactured and sold by other companies than the original manufacturer that had the patent. For example, the active ingredient mancozeb is off-patent and sold by Bayer under the brand name Dithane. However, there are dozens of brands and products with mancozeb, which all in theory have the same active ingredient and mode of action.

In addition, farmers often rely on the credit provided by agro-retail shops to buy inputs such as fungicides. Hence, the relationship retailer-farmer goes beyond the general salesclient relationship, but both are intrinsically and financially interlinked. The relationship is 


\section{GE周POTaTO}

based on mutual trust: the retailer gives input loans to farmers who expect to get best input and advice allowing to pay back the loan after harvest. The success of a farmer means that retailer loans are paid back. Because of the key role that agro-retail shops currently fulfill in pesticide advice and rural financing it is important to understand how the GEOPOTATO service affects or supports these roles of agro-retailers. Finally, it is interesting to assess how the use of fungicide brand names in the GEOPOTATO alerts affects brand recognition and sales of agro-input dealers.

\subsection{Collaboration with Bayer Crop Science}

In collaboration with Bayer Crop Science Ltd in Bangladesh, the GEOPOTATO service was used in 2017-2018 and 2018-2019 under a small group of farmers to test the effect of using fungicide brand names in the SMS / Voice mail alerts. Two upazillas Badarganj and Pirganj of Rangpur district were selected purposively in 2018-2019 as study area as per Bayer's request. This district is one of the leading potato producing area of Bangladesh. In 20182019, farmers in Badarganj cultivated 2,720 hectares with potato producing 59,615 MT; Farmers in Pirganj cultivated 4,000 hectares with potato producing $93,750 \mathrm{MT}$. In the 20182019 season, 3,359 farmers Badarganj and 2,205 in Pirganj were registered GEOPOTATO service users. Together with Bayer staff a sequence of branded SMS / Voice mail alerts was designed including only Bayer products. The messages were formulated like the following:

GEOPOTATO.
প্রিয় কৃষক, বর্তমান
আবহাওয়ায় আলুর
মড়ক রোগ আক্রমনের
সম্ভাবনা সবচেয়ে বেশি।
আগামী ৩ দিনের মধ্যে
ছত্রাকনাশক সিকিউর
সঠিক পরিমাণে ও
সঠিক নিয়লে প্রয়োগ
করুন। - জিওপটেটো।

"Dear Farmer, the current weather
conditions are conducive for late
blight infection. Please spray
fungicide Secure in the right method
and right amount within 3 days.
- GEOPOTATO"

The first six SMS / Voice mail alerts had the following product names: 1) Antracol ${ }^{\circledR}, 2$ ) Dithane ${ }^{\circledR}$ M 45, 3) Melody ${ }^{\circledR}$ Duo, 4) Melody ${ }^{\circledR}$ Duo, 5) Secure ${ }^{\circledR} 600$ WG, 6) Secure ${ }^{\circledR} 600$ WG. The consecutive sequence of Melody Duo and Secure was repeated in case more than six alerts were sent in an area. 


\section{Objectives}

The main aims of the survey under local agro-retailers were the following:

1. Gain insight into the effect of promoting Bayer fungicides with GEOPOTATO alerts among farmers on retailers' brand recognition and knowledge.

2. Assess the effect of the Bayer-branded GEOPOTATO alerts on retail sales of Bayer fungicides. 


\section{Methodology}

Two surveys under local agro-retailers in Pirganj and Badarganj were carried out:

1. Baseline Survey (Annex I): The baseline was conducted from 29 November to 5 December 2018 among 137 retailers (70 from Badarganj and 67 from Pirganj) by enumerators using a set of open-ended and closed questions to understand awareness about Bayer brand before the potato season.

2. Endline Survey (Annex II): The endline was conducted after the potato season between 15 and 21 May 2019. The same retailers were approached as in the baseline, 124 retailers (64 from Badarganj and 60 from Pirganj) were available in the endline survey.

The enumerators selected the retailers (respondents) and were not guided by Bayer staff or local extension staff. The data were collected by the enumerators in face-to-face interviews with owners of agro-input retail shops. Before interviewing, the aims of the study were explained to the respondents. The enumerators did all effort to set up a friendly and trust relationship with the respondents. As a result, respondents were convinced that the study was purely an independent market research and did not have an adverse effect on their business. 


\section{Results}

This report gives the survey results of 124 retailers who took part in both the baseline and endline survey. The retailers who did not take part in the endline have been excluded from the analysis. Hence in all graphs $n=124$.

\subsection{Agro-input retailers' knowledge of fungicide company names}

In the baseline, we asked retailers the company names whose fungicide products they sell. Retailers could choose multiple companies. The enumerators did not prompt any choice, but recorded retailers' answers from a predefined list with 30 companies selling fungicides in Bangladesh. In addition, retailers could add companies if they were not on the list. The results are shown in Figure 1. Before the potato season, Padma, Autocrop, National, Syngenta and Alpha Agro were most often mentioned companies, followed by Bayer. Caution must be applied in interpreting the data as in some cases retailers sell fungicides without recognizing the company name. Therefore, the data shows retailers' knowledge about companies that sell fungicides.

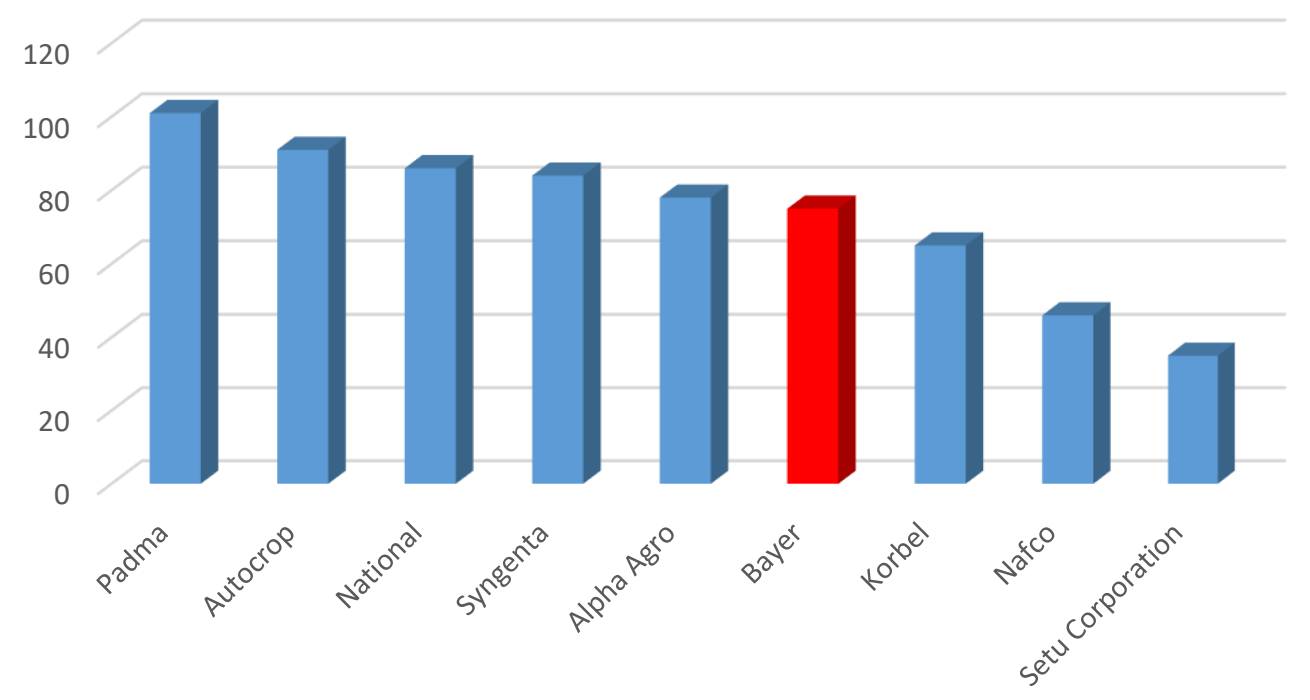

Figure 1: Number of times company names that sell potato fungicides were mentioned by local agro-input retailers in Pirganj and Badarganj (baseline survey).

In the endline survey, we asked the retailers what company products they sold as potato fungicide in the last season (Figure 2). Like in the baseline, retailers could choose multiple options and enumerators did not prompt any choice. Bayer stands top in terms of number of retailers selling (or recognizing to sell) fungicides to be used in potatoes. 


\section{GEจำคTato}

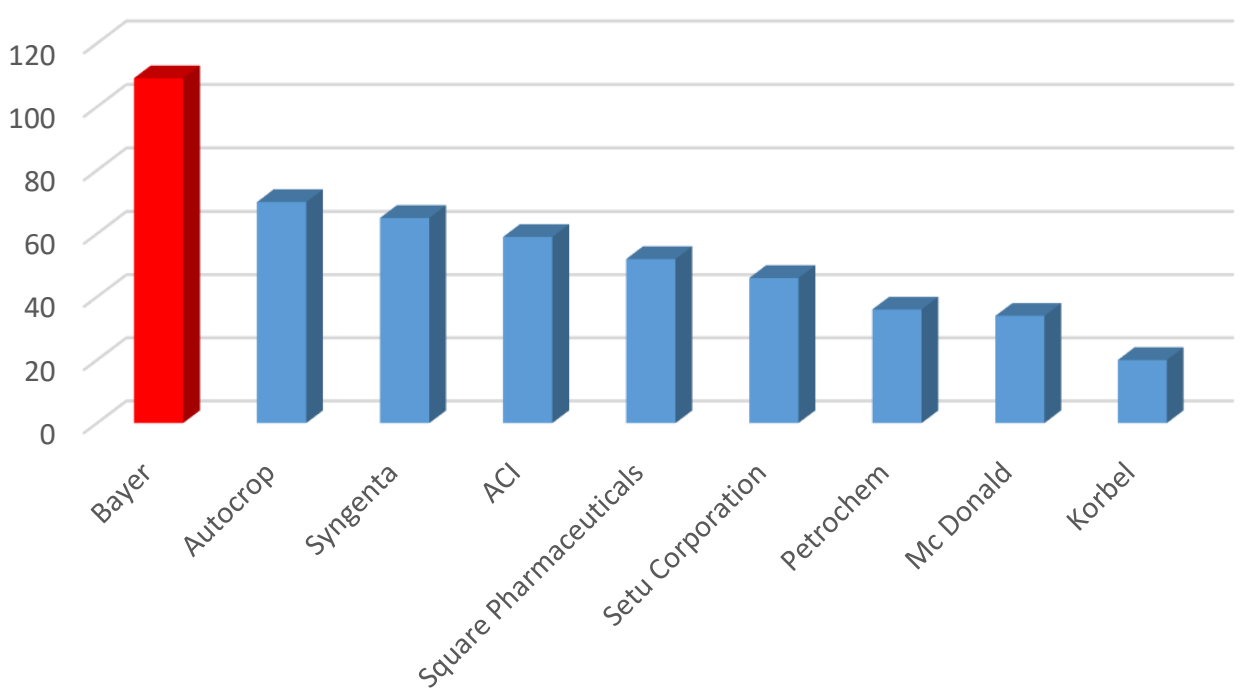

Figure 2: Number of times company names that sell potato fungicides were mentioned by local agro-input retailers in Pirganj and Badarganj (endline survey).

In a potato season (2018-2019) with low late blight risks, 34 retailers out of a total 124 retailers reported to sell (or recognizing to sell) Bayer products for the first time. This is $45 \%$ increase in the total number of retailers selling potato fungicide.

\section{2 'Top of Mind' brand}

We investigated which fungicide brands were recalled by agro-input retailers spontaneously without providing a pre-defined list with fungicide brands. Results give insight in the 'top of mind' fungicide brands under retailers in the study area.

In the baseline, only 34 of the 124 surveyed retailers (27\%) reported spontaneously Bayer products as potato fungicide in earlier seasons. The rest of the retailers (73\%) reported non-Bayer products as 'top of mind' potato fungicides (Figure 3).

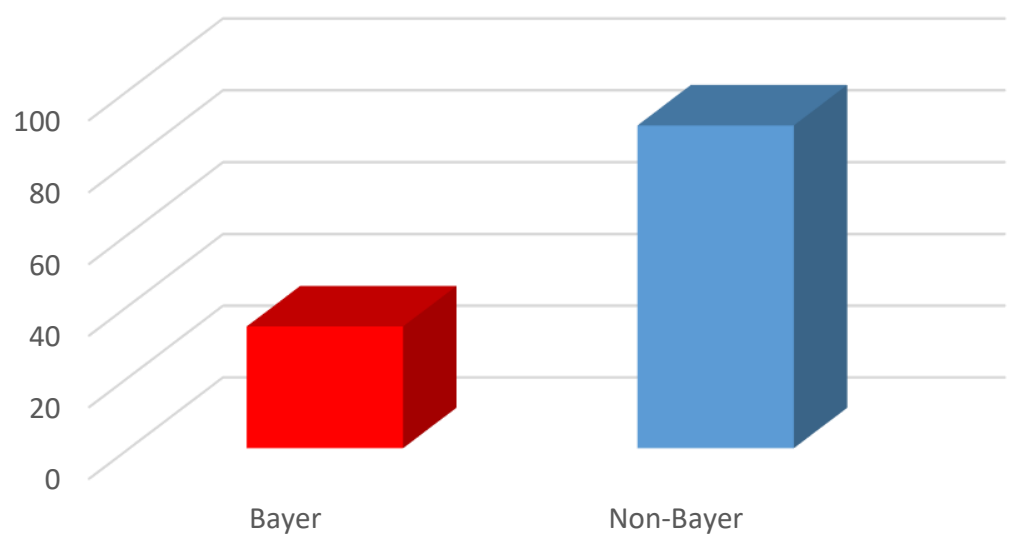

Figure 3: The number of retailers that recalled Bayer and non-Bayer products spontaneously before the potato season 2018-2019. 


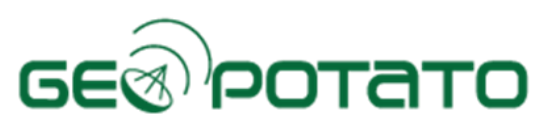

In the endline survey, we asked retailers to indicate the first 'Top of Mind' brand, second 'Top of Mind' brand and third 'Top of Mind' brand (Figure 4).

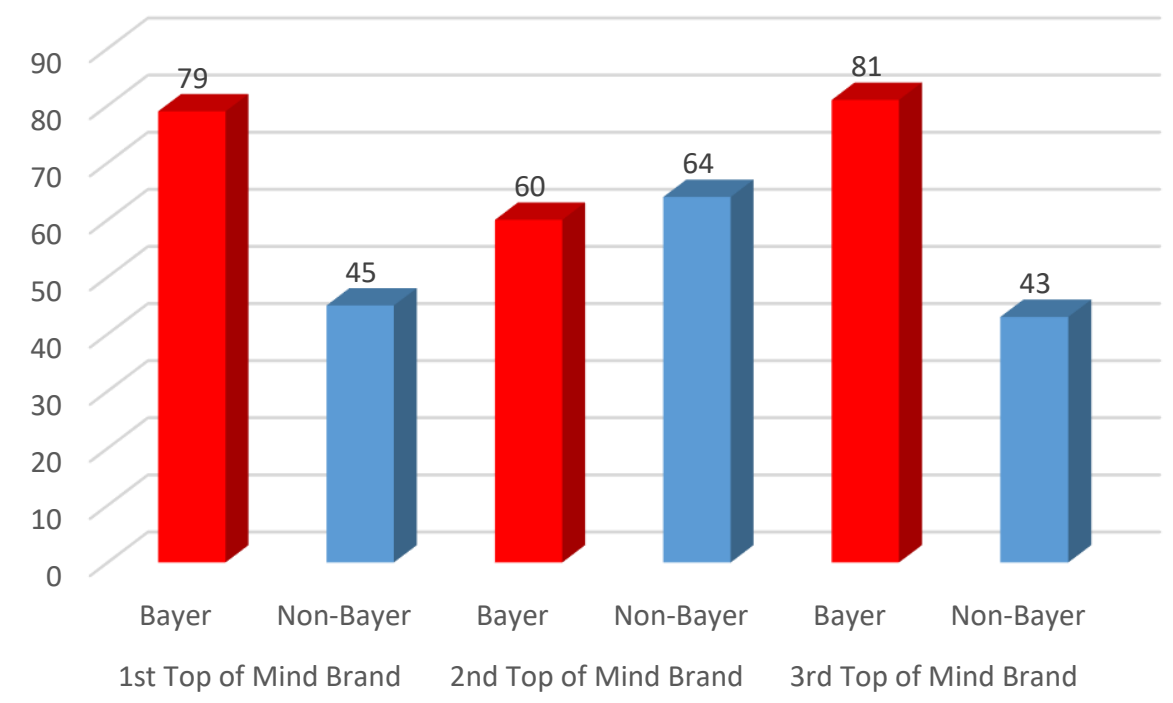

Figure 4: The number of retailers that indicated Bayer and non-Bayer products after the potato season 2018-2019.

Figure 4 shows that:

I. 79 out 124 respondents (64\%) indicated Bayer products as first 'Top of Mind' fungicide brand.

II. 60 out 124 respondents (48\%) indicated Bayer products come as second 'Top of Mind' fungicide brand.

III. 81 out 124 respondents (65\%) indicated Bayer products as third 'Top of Mind' fungicide brand.

Comparing Figure 3 and 4, we can conclude that the branded advice has increased the popularity of the Bayer brand under agro-retailers in Badarganj and Pirganj considerably: In the baseline only $27 \%$ of the retailers mentioned Bayer spontaneously as 'top of mind' brand, while in the endline survey $64 \%$ of the retailers did so.

\subsection{Change in Bayer fungicide product sales}

In the Baseline survey we asked retailers about the specific Bayer products they sold in the earlier season. We asked the same question in the endline survey to assess differences in sales. 


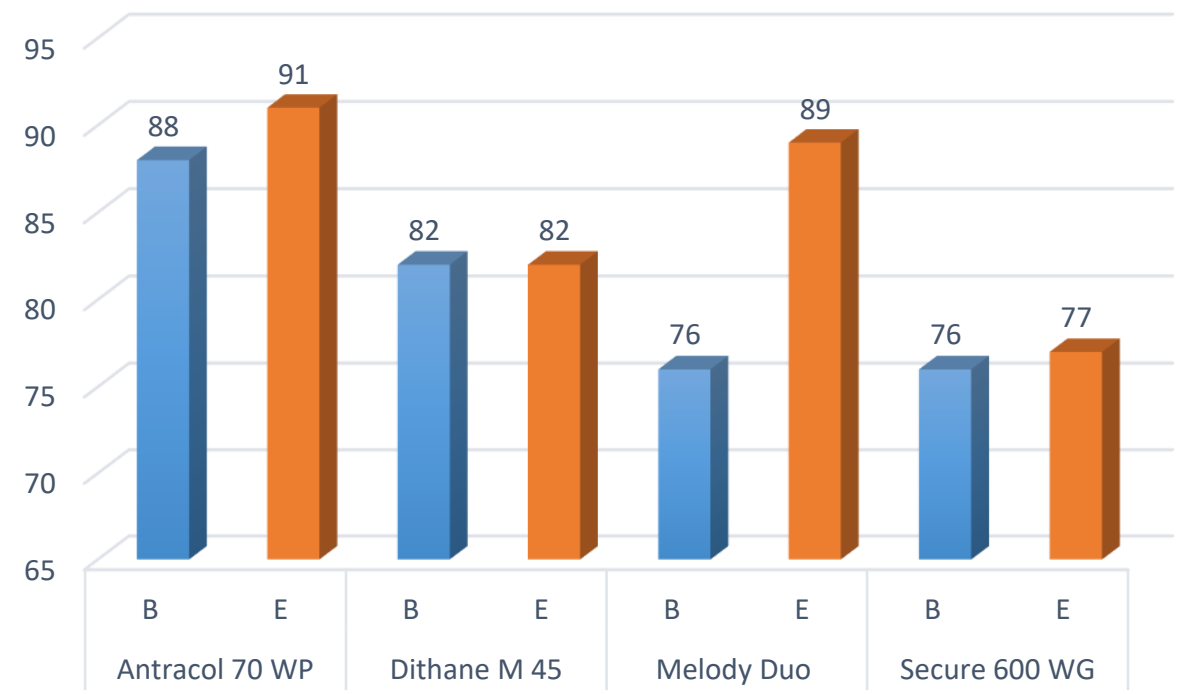

Figure 5: The number of retailers that sold specific Bayer fungicide products before and after the potato growing season 2018-2019 in Badarganj and Pirganj. B=Baseline, E=Endline

Figure 5 shows that 88 out of 124 retailers (71\%) retailers reported in the baseline that they sold Antracol in earlier seasons. After the 2018-2019 potato season, $73 \%$ retailers reported to have sold Antracol. Changes were also small in the number of retailers selling Dithane M45 and Secure 600 WG. However, 10\% more retailers reported to have sold Melody Duo during the last potato season.

\subsection{Impact of GEOPOTATO branded message on sales of Bayer products}

To understand the effect of GEOPOTATO branded SMS / Voice mail on sales of Bayer products, we asked the retailers several questions in the endline survey.

One of the questions was 'Have farmers shown you the SMS about Bayer products on their mobile phone while they visited your shop for purchasing fungicides?' Among 124 respondents (retailers), 90 responded 'yes', i.e. $71 \%$ of the retailers reported they came across Bayer branded GEOPOTATO alerts in farmer's phone (Figure 6).

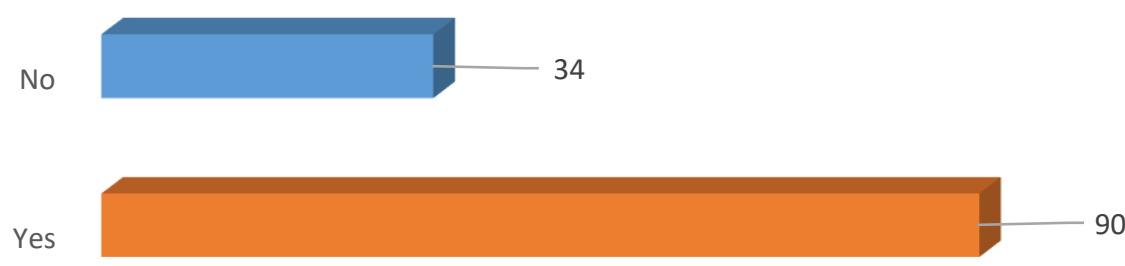

Figure 6: The number of retailers in Badarganj and Pirganj that have seen GEOPOTATO messages received by farmers in the 2018-2019 season. 


\section{Geจीротато}

Retailers who said that they came across the GEOPOTATO recommendation (70\%) were asked if they sold the Bayer fungicide that was recommended in the GEOPOTATO SMS. Among three options, $51 \%$ of the retailers sold the branded fungicide 'sometimes', $35 \%$ of the retailers sold 'always' the advised Bayer product. Only $14 \%$ of the retailers 'never' sold the advised Bayer product (Figure 7).

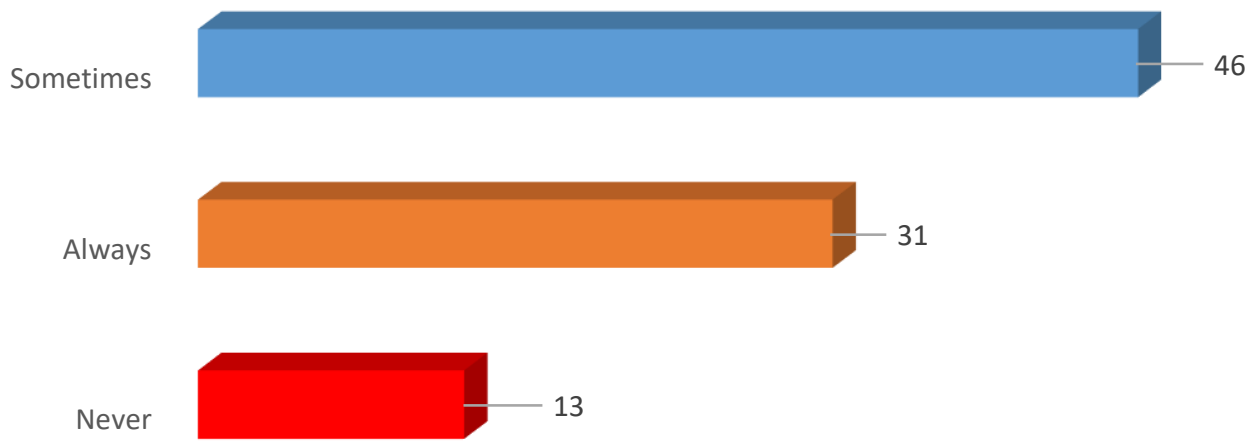

Figure 7: Number of retailers that were shown the GEOPOTATO SMS advice by farmers and sold then the recommended Bayer product. 


\section{Conclusions}

Commercial agricultural information service systems in Bangladesh are nonexistent because paying for information by farmers is not yet an accepted idea. From a long-term perspective, agro-input companies like Bayer can promote sustainable and proper input use through using ICT and at the same time promote own products as done in the GEOPOTATO pilot in Badarganj and Pirganj. The results of the pilot in the 2018-2019 season show that:

- Knowledge of Bayer among local retailers has increased after one season with GEOPOTATO branded SMS / Voice mail alerts (Figure 1 and 2).

- Branded GEOPOTATO recommendations have placed Bayer products at the 'Top of Mind' brand among retailers (Figure 3 and 4).

- More local retailers sold Bayer products in the 2018-2019 season. Especially more retailers sold Melody Duo than in earlier seasons (Figure 5).

- More than $70 \%$ of the retailers have seen the GEOPOTATO SMS messages shown by farmers and more than $80 \%$ of these retailers sold sometimes or always Bayer products (Figure 6 and 7 ). 


\section{References}

Katalyst, 2012. Making ICT work for Bangladesh farmers. Case study number 6 . The Katalyst cases http://www.katalyst.com.bd/wp-content/uploads/2014/11/Case-Study-Number6 3rd-version-3-12-2012.pdf

Rahman, M.M., Dey, T.K., Ali, M.A., Khalequzzaman, K.M. and Hussain M.A., 2008. Control of Late Blight Disease of Potato by Using New Fungicides. International journal of sustainable crop 3(2):1015. 


\section{Annex 1: Baseline Questionnaire}

1. Name of the Retailer

2. District

3. Upazila

4. Union

5. Contact No

6. Which company's Fungicide you sell for potato?

7. Which fungicide brands you usually sell for potato?

8. Which fungicide are the most popular?

9. Have you heard about Bayer?

10. Have you ever sold Antracol?

11. Have you ever sold Dithane M45?

12. Have you ever sold Melody Duo?

13. Have you ever sold secure?

14. Please snap and upload more than one photo of the shelf

15. Geolocation of the retail Shop 
Annex 2: Endline Questionnaire

1. Name of the Retailer

2. District

3. Upazila

4. Union

5. Contact No

6. What company's fungicide you sell for in last potato season?

7. What fungicide brands you sold in last potato season?

8. What fungicide was the most popular in last potato season?

9. What fungicide was the second most popular in last potato season?

10. What fungicide was the third most popular in last potato season?

11. Have you heard about Bayer Crop Science?

12. Which Bayer products were sold most in last potato season?

13. Does farmers were more interested to purchase Bayer products in last potato season?

14. If Yes than what percentage of farmers purchase Bayer fungicide in last potato season?

15. Have farmers shown you the SMS about Bayer products in their mobile phone while they visited you for purchasing fungicide?

16. Have you sold the Bayer product to the farmer as mentioned in the SMS recommendation?

17. If yes, why did you sell it to the farmer?

18. Please snap and upload more than one photo of the shelf

19. Geolocation of the retail Shop 